\title{
An Emerging Model for Virtual International Academic Conference in Architecture, Engineering, and Construction
}

\author{
Yanqing Fang ${ }^{1 *}$ and Emmanuel Itodo Daniel ${ }^{2}$ \\ ${ }^{1}$ School of Management Science and Engineering, Tianjin University of Finance and Economics, Tianjin, China, ${ }^{2}$ School of \\ Architecture and Built Environment, Faculty of Science and Engineering, University of Wolverhampton, Wolverhampton, \\ United Kingdom
}

OPEN ACCESS

Edited by: Hongling Guo,

Tsinghua University, China

Reviewed by: Ahsan Nawaz,

Zhejiang University, China

Dong Zhao,

Michigan State University, United States

*Correspondence: Yanqing Fang

fangyq_/c@sina.com

Specialty section:

This article was submitted to Construction Management,

a section of the journal

Frontiers in Built Environment

Received: 28 April 2021

Accepted: 29 July 2021

Published: 10 August 2021

Citation:

Fang Y and Daniel El (2021) An

Emerging Model for Virtual

International Academic Conference in

Architecture, Engineering,

and Construction.

Front. Built Environ. 7:701755.

doi: 10.3389/fbuil.2021.701755
Academic conferences are very important to industrial development and academic scholars. However, the coronavirus disease 2019 pandemic has led to the cancellation of many international conferences; thus, virtual conferences have received a great deal of attention. Their expanding role has created an urgent need to explore the best approaches for successful execution. However, there is limited empirical evidence on the organization of these conferences. This study aims to offer a comprehensive analysis of the key success factors through a case study of the International Group for Lean Construction's first virtual conference. The results revealed the influence of multiple factors. In addition, a successful model for an international virtual academic conference is proposed. The model contributes to the knowledge of sustainable development in engineering management and architecture, engineering, and construction practice.

Keywords: COVID-19, virtual conference, influence factors, case study, IGLC, success model

\section{INTRODUCTION}

International academic conferences on architecture, engineering, and construction (AEC) are very important to academic and industrial development scholars. Attending conferences and presenting papers are central to academic and industrial research (Neustaedter et al., 2016). More important, academic conferences provide opportunities for scholars to communicate and to exchange information about developments in their subject areas. International academic conferences usually require the participation of representatives from several countries. However, after coronavirus disease 2019 (COVID-19) was identified, it quickly became a pandemic that affected all aspects of life (Nawaz et al., 2020a), including international academic conferences on AEC. In 2020, there were more than 85 million confirmed COVID-19 cases worldwide (World Health Organization, 2020). The World Health Organization advocated avoiding large gatherings to avoid exposure to the virus and to reduce its spread. This led to the cancellation or postponement of many international academic conferences. For example, the AIA Conference on Architecture (originally scheduled for May 14-16, 2020) was postponed, and the 108th Annual Meeting of the Association of Collegiate Schools of Architecture was rescheduled as a virtual event.

COVID-19 has caused many institutions around the world to reassess their processes and to adjust their approaches to conducting business (Stambough et al., 2020). Guidelines are urgently needed for international academic conferences to successfully navigate the increasingly complex environmental challenges. Virtual conferences are becoming the norm, and they are gaining the 
support of researchers (Viglione, 2020). Online formats, which are considered to be environmentally friendly, have been found to be acceptable alternatives to in-person conferences (Arnfalk et al., 2016; Viglione, 2020).

Founded in 1993, the International Group for Lean Construction (IGLC), an international network of applied and academic researchers in AEC, has called for radical changes in practice, education, and research to respond to the global challenges ahead. The locations of the annual conferences rotate among continents (IGLC, 2020). The first 27 IGLC conferences, which were held every year as scheduled, led to many theoretical and practical achievements. Because of the COVID-19 pandemic, the organizers in Peru asked for the 28th conference (IGLC 28) to be rescheduled for 2021. More than one hundred conference papers were being developed in anticipation of the 2020 conference. Individuals from the United States and the United Kingdom volunteered to rapidly develop the information technology infrastructure and conference organization protocols to allow IGLC28 to be held virtually in 2020 .

Several studies have discussed the benefits, implementation effects, and best practices associated with virtual conferences (Porpiglia et al., 2020; Rubinger et al., 2020; White, 2014). However, the discussion on these issues has only just begun. There is no clear understanding of the role of these factors in the successful execution of a virtual international academic conference (VIAC) on AEC. Indeed, there is limited research on the key success factors. This study used the case of the first virtual IGLC conference to address the following two research questions:

- What were the contributory factors to the success of the first virtual IGLC conference?

- What is the model for a successful VIAC on AEC?

The COVID-19 pandemic has brought a great deal of attention to VIACs in AEC; thus, an exploration of the key success factors is necessary. Given the paucity of empirical evidence, this study performed a comprehensive analysis of the critical success factors and proposed a model for the successful execution of a VIAC in AEC.

\section{LITERATURE REVIEW}

\section{International Academic Conferences}

The scientific collaboration that results from conferences can be more promising than projects by small groups of researchers in single institutions (Rubinger et al., 2020). International academic conferences usually require the participation of representatives from multiple countries. Scholars have given increased attention to these conferences because of the opportunities to track research progress, to present their work, to learn from their peers, and to gain insights and receive suggestions from other scholars to achieve their professional, personal, and social goals (McCarthy et al., 2004). Therefore, this kind of face-to-face communication could create new opportunities for collaboration. Increasing emphasis has been placed on impact evaluations of the social function of conferences (Spilker et al., 2020; Wang et al., 2017).

Attendance at international academic conferences is considered an act of academic citizenship (Macfarlane, 2007; Spilker et al., 2020). In the regions in which they are held, there are significant economic effects (Sugiyama et al., 2019), which have provoked the opposition of environmental advocates. The COVID-19-related travel restrictions and concerns about disease spread have added a new dimension to the organization of international academic conferences (Viglione, 2020).

\section{Effects of Virtual International Academic Conferences}

In the COVID-19 era, virtual conferences seem to be a safer and more attractive alternative (Porpiglia et al., 2020). Virtual conferences have no designated locations, and the direct costs are low (Richards et al., 2012). The participants are subject to fewer time constraints (Koch et al., 2012), and global accessibility is improved. A VIAC has the potential to engage and to connect professional peers and facilitators across traditional geographical boundaries (Murphy and Reushle, 2012) because of the opportunities to interact and to exchange information with colleagues in real time on the new digital platforms (Porpiglia et al., 2020). However, achieving the social effects of face-to-face events in virtual interactions has been difficult (Bidmon et al., 2020). Factors such as time zone differences and human contact, affections, and emotions cannot be fully replicated (Porpiglia et al., 2020). Face-to-face conferences have been found to offer many opportunities that cannot be replicated by virtual events (Viglione, 2020). Porpiglia et al. (2020) raised the question of a paradigm shift in the organization of traditional and virtual conferences in the COVID-19 and post-COVID-19 eras. Bidmon et al. (2020) asserted that online conferences should be seen as a different mode of academic communication rather than a substitute for face-to-face conferences. Time is needed to develop the logic and structures for online interactions. Virtual conferences have received little attention because of the newness of the phenomenon (Erickson et al., 2011).

\section{Influential Factors in Successful Virtual International Academic Conferences}

The quality of the outcomes of an international conference depends on not only successful execution but also influential internal and external factors (Simpson and Nielsen, 2005). These concerns have also applied to VIACs. The key factors in successful virtual conferences have been analyzed from four main perspectives: 1) virtual conference tools, 2) participants' social interactions, 3) virtual organizations or teams, and 4) designs and controls.

Virtual conference tools enable the synchronous exchange of e-resources globally through interactive audio, chats, video, and presentations (Koivulahti-Ojala and Käkölä, 2012). The characteristics of the communication tools influence the quality and effectiveness of virtual meetings (Mulyani, 2019). 
Social media websites have provided opportunities for social interaction because of the opportunities to share information and to express personal feelings (Hara et al., 2000; Pookulangara and Koesler, 2011). Functional, social, and information communication media are three important factors in successful remote collaboration (Navarro, 2001). When used appropriately, social media can improve information flow. However, they do not necessarily facilitate understanding, commitment, or knowledge sharing. They can create language barriers to clear communication (White, 2014).

Virtual organizations or teams play a vital role in the success of virtual conferences (White, 2014). Team training is considered an important factor (Vandenberg and Reese, 2011). Chen et al. (2007) stated that brief training enables participants to design and to facilitate virtual conferences to improve team performance. Beranek and Martz (2005) found that a virtual team that received relational link training exhibited greater cohesion and satisfaction with the team outcomes and the virtual conference process. The effectiveness of virtual conferences depends on the organization's perceptions of virtual maturity, as well as the virtual toolbox, behavior, and rebound effect (Lindeblad et al., 2016). White (2014) emphasized the role of practice sessions in participants' familiarity with team members' speech and behavior patterns prior to collaboration. Team members also play a significant role in influencing the meeting outcomes. The more influential the participant, the greater is their effect on the outcomes (Rienks et al., 2006). Team leaders need to understand the team members in order to establish close working relationships (White, 2014). Conference moderators can address participation and cultural issues and suggest approaches for improving communication and online learning environments (Starr-Glass, 2014).

Participants in virtual conferences face physical, intellectual, and emotional challenges (White, 2014). Thus, attention must be paid to conference design and control. Pre- and post-training assignments, well-trained hosts, guidelines and checklists, preconference equipment checks, virtual office hours, and immediate friendly support are key success factors (Vandenberg and Reese, 2011). A virtual conference session lasting more than 1 hour is unlikely to be successful. Thus, constructive discussions, conclusions, and additional plans to control timeouts are important design and control elements (White, 2014).

The influential factors in the execution of VIACs have been addressed; however, their nature and roles remain unclear. This study aimed to fill this gap through a comprehensive analysis of the influential factors a proposed model for a successful VIAC in AEC.

\section{RESEARCH METHODOLOGY}

According to Nawaz et al. (2020b), qualitative analysis allows for the development of themes or factors and the exploration of their interrelationships. A case study in which evidence was aggregated from multiple sources was adopted for the current project. A case study allows for an in-depth description of a phenomenon. This could extend theory or contextualize the phenomenon (Siggelkow, 2007). Thus, the case study was used to facilitate a detailed examination of the VIAC, the development of theories, and the identification of new research directions (Siggelkow, 2007). Evidence was gathered from multiple sources to reduce the limitations associated with single-case studies (Yin, 2014).

The study began with a literature review, which integrated the existing information to provide solutions to new research problems (Nawaz et al., 2019). The cited articles identified the influential factors in virtual conferences and provided empirical evidence for the appropriate application of case studies (Daniel et al., 2019). The corroboration of the perspectives of previous studies and the results of the present case study enhanced reliability. Figure 1 presents the study design.

\section{Case Selection}

The case selected for this study was IGLC 28. Since 1993, the IGLC has held 27 annual in-person conferences with established procedures (IGLC, 2020). However, IGLC 28 was held virtually, and this provided an opportunity to explore the issues associated with the organization of a VIAC.

\section{Data Collection}

The data were collected from three sources: participant observation, semi-structured interviews, and documentary evidence. According to Yin (2014), multiple confirmatory data sources create an evidence triangle to make the research results more accurate, convincing, and explanatory (Yin, 2014). The purpose of this study was to assess the key success factors in a VIAC and to develop the most appropriate execution mode. Therefore, it was necessary to analyze specific events.

Participant observation provides opportunities to obtain participants' detailed descriptions of the events and group interactions, to gain an insider's perspective through observation, and to control some small situations. However, the main problem is the possibility of bias and, thus, lack of objectivity because of the researcher's involvement (Yin, 2014). Therefore, semi-structured interviews and documentary evidence were also used to make the data collection robust. The research team carefully identified the influential factors in the IGLC's first virtual conference through documentary evidence, in-depth interviews, and participant observation to restore the authenticity of the event to the greatest extent.

\section{Semi-structured Interviews}

Semi-structured interviews can ensure that the respondents' answers do not deviate from the research questions. Openended questions can reduce response bias and enrich survey results (Daniel et al., 2019). Purposive sampling was used in the semi-structured interview. To achieve the research objectives, the interviewees were selected on the basis of their knowledge regarding the research questions (Bryman, 2012). The interviews addressed the research questions and the respondents' backgrounds. Participation was voluntary. The interviews were conducted through email. The email responses allowed the respondents to provide their views on the research question. Ten participants were interviewed (see Table 1).

\section{Documentary Evidence}

The research team collected many electronic pieces of evidence, including the conference website, published proceedings, video 


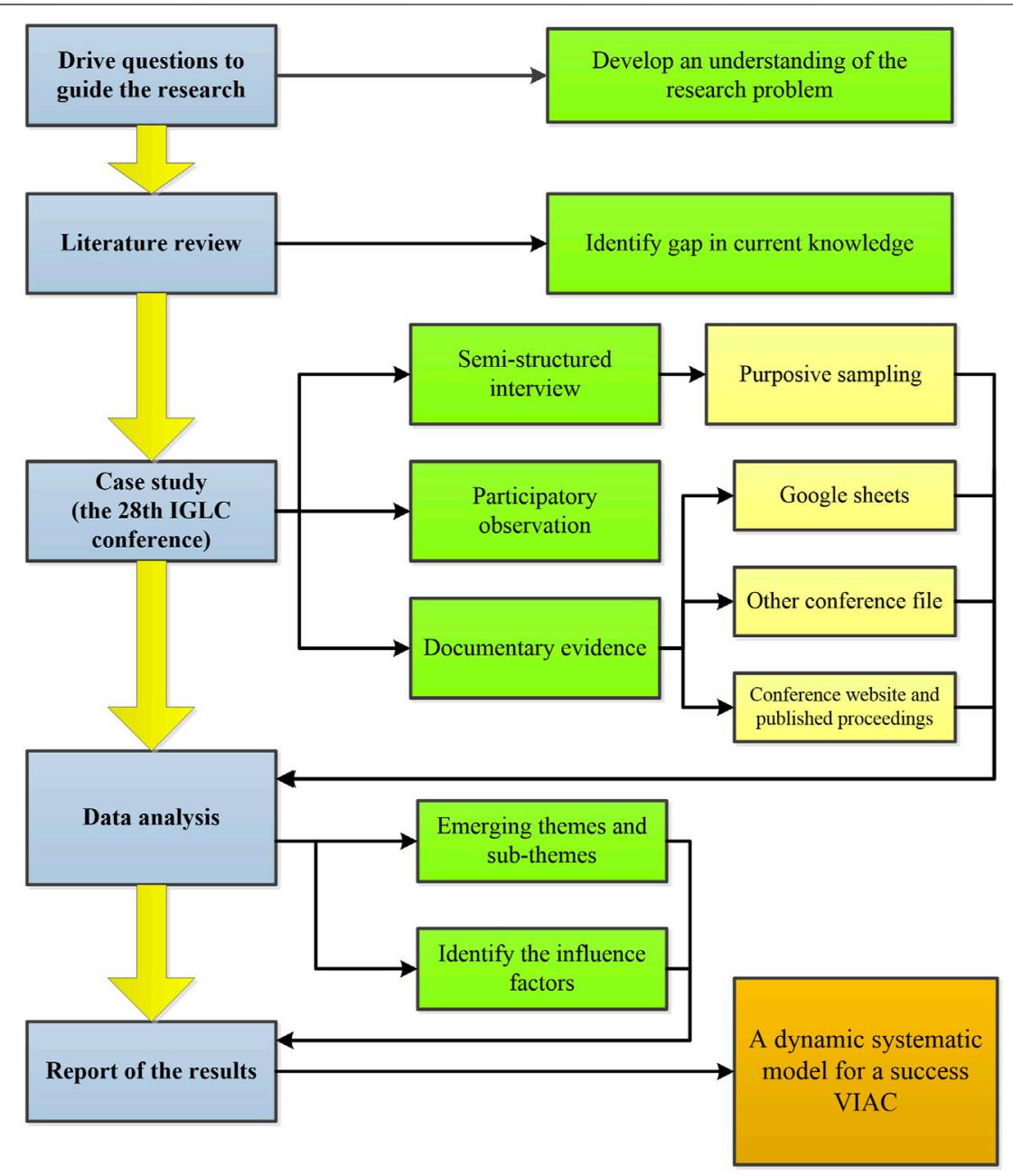

FIGURE 1 | Conceptual representation of the research design.

TABLE 1 | Information on participants in semi-structured interviews (Note: Sessions lasted $\sim 60 \mathrm{~min}$ each).

\begin{tabular}{cllc} 
Code & Conference role & $\begin{array}{c}\text { Previous or initial } \\
\text { participation in IGLC } \\
\text { conference }\end{array}$ & $\begin{array}{c}\text { Number } \\
\text { of sessions attended }\end{array}$ \\
\hline IP01 & Participant & Previous participation & $6 / 21$ \\
IP02 & Participant & Previous participation & $4 / 21$ \\
IP03 & Participant & Initial participation & $21 / 21$ \\
IP04 & Participant & Initial participation & $1 / 21$ \\
IP05 & Participant & Previous participation & $10 / 21$ \\
IP06 & Participant & Previous participation & $4 / 21$ \\
IP07 & Participant & Initial participation & $18 / 21$ \\
IP08 & Participant & Initial participation & $7 / 21$ \\
IP09 & Participant & Initial participation & $12 / 21$ \\
IP10 & Participant & Previous participation & $21 / 21$
\end{tabular}

recordings, and social media posts. The multi-level and multi-source data collection method was used to cross-check the interviews and control the backtracking bias. This triangulation facilitated validation, thereby enhancing the accuracy of the results (Yin, 2014).

\section{Data Analysis}

First, the interview data were transcribed. The data were then analyzed and coded to ensure reliability and validity. Themes and codes emerged from the analysis of the interviews and research questions. New themes continued to emerge until the coding was completed and all the themes were presented. The XMind mapping tool (XMind 8) was used to build a subject tree. Each topic was developed as a new branch. Microsoft Excel was used to organize the participants' answers. Data analysis and coding were completed independently by two coders. Coding consistency met the requirements of the inter-rater reliability principle proposed by Boyatzis (1998), and the results were reliable ( $\mathrm{Li}$ et al., 2020). The data sources and codes are provided in Table 2.

\section{The Case Study}

Basic Characteristics of the 28th International Group of Lean Construction Conference

Because of the COVID-19 pandemic, IGLC 28, which was originally scheduled to be held in Peru, transitioned to a 
TABLE 2 | Case data sources and codes.

\begin{tabular}{|c|c|c|c|}
\hline case & & Data sources & Codes \\
\hline \multirow[t]{5}{*}{ 28th virtual IGLC conference } & 1. Semi-structured interview & & IP01-|P10 \\
\hline & 2. Participant observation & & $\mathrm{PO}$ \\
\hline & 3. Documentary evidence & (1) Google Sheets & GS \\
\hline & & (2) Other conference files (video recordings, conference e-mail, conference papers, etc.) & OF \\
\hline & & (3) Conference website and published proceedings & $\mathrm{CN}$ \\
\hline
\end{tabular}

Note: IP, interview participant; PO, participant observation; GS, Google Sheets; OF, other files; CN, conference net.

TABLE 3 | Basic characteristics of the 28th International Group of Lean Construction conference.

case attributes

Nature of the conference

Duration of the conference

Number of accepted papers

Number of countries or regions from which paper were accepted

papers

Total number of hours

Number of registrants

Number of sessions

Number of parallel sessions

Numbers of themes/tracks 28th IGLC conference

Virtual conference
July $6-12,2020$ (including summer school)
89
22
Approximately $40 \mathrm{~h}$
200
21
0 (IGLC 28 was a single-track conference)
18 (two of the themes were addressed in two and three sessions, respectively; the remaining themes each
lasted one session)

virtual format. Table 3 presents the basic characteristics of this first virtual IGLC conference.

\section{Conference Design Process}

The virtual conference featured presentations by 89 authors across seven plenary and fourteen breakout sessions. Each session was led by a moderator, and there were breaks between sessions. All the live discussions used the Zoom virtual meeting platform, and the schedule was based on the Pacific Time Zone. The participants were asked to read the conference papers and watch video presentations of the papers ahead of the discussions. Thus, the conference organizers made all the conference papers and video presentations available before the live discussions.

To make the live discussions efficient and effective on Zoom, Google Sheets was set up for questions to be submitted up to $24 \mathrm{~h}$ before the scheduled discussions. This gave the moderators and presenters time to review the questions. The moderators determined the question sequence during the live discussions. The plus-delta tool in Google Sheets facilitated the collection of data on the value of each session for the attendees. It was also used to collect other feedback, such as ideas for improvement.

The conference agenda and guide were sent in advance to the participants via email. The conference schedule and the papers discussed in each session were easily reviewed and downloaded via links in Google Sheets. The conference focused on workflow and procedures. Recordings of the sessions were uploaded for participants who missed the online discussions or wanted to review them to better understand the content. The conference papers were also uploaded to the official website (http://iglc.net) for knowledge storage. The IGLC provides open access; therefore, the papers can be downloaded.

\section{RESULTS AND DISCUSSION}

The study aimed to explore the key success factors in VIACs and to develop a dynamic model for their execution. The results were generated from the analysis of the themes that emerged from the different data sources, which were confirmatory. A map of the themes and their sources is presented in Figure 2. The themes and subthemes are discussed below.

\section{Emergent Themes and Subthemes From Semi-structured Interviews}

The analysis of the Google Sheets document and semi-structured interviews yielded core themes and subthemes related to the organization of a successful VIAC and the key success factors in the first virtual IGLC conference. The themes were enablers, barriers or challenges, effects, and external environmental factors.

\section{Enablers of the Virtual Conference}

Enablers are the factors that contributed to the success of the virtual conference and mitigated the negative effects of the barriers or challenges (Ozorhon et al., 2014). The subthemes regarding the enablers emerged from the semi-structured interviews. They are discussed in the succeeding sections.

\section{Availability and Ease of Use of Technology (Technology Enablers)}

The analysis of the semi-structured interview and Google Sheets data revealed the importance of the availability and ease of use of technology in a virtual conference. For example, a respondent stated that Google Drive, a common resource that was used 


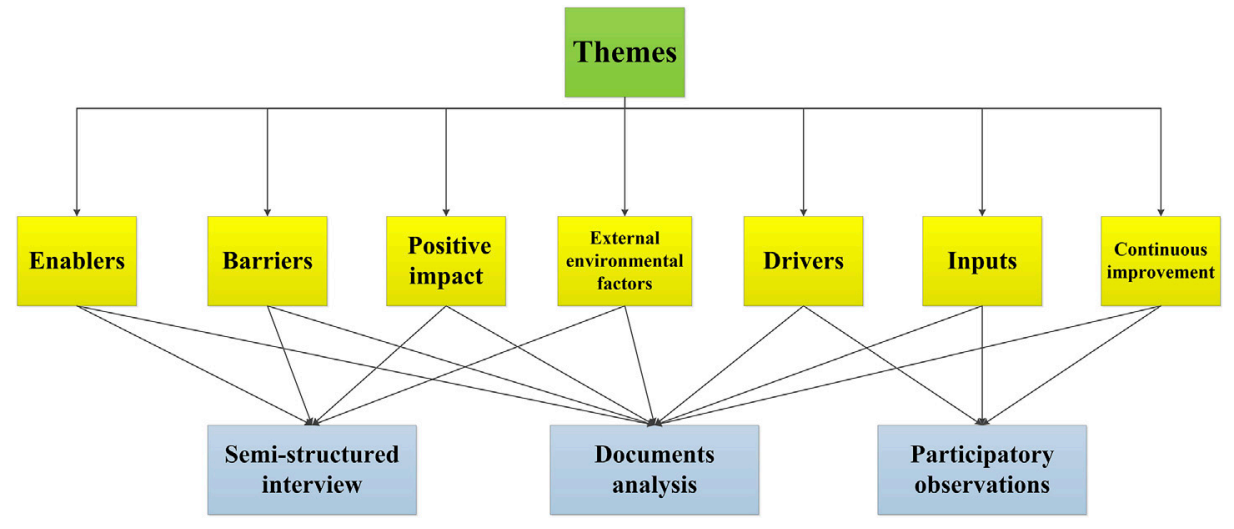

FIGURE 2 | Map of the themes and their sources.

worldwide, reduced the awkwardness of conference operations (IP07). Another respondent stated that the digital interface was delightful and allowed them to easily share ideas and comments (IP08). The role of technology in communication was a recurring theme in the semi-structured interviews. An interviewee stated, "Technological tools and applications also enhanced communication and facilitated the engagement of participants and organizers and, ultimately, the amount of information" (IP09).

The analysis of the Google Sheets document revealed the recurrent theme of technology as a factor. A participant said, "Google Sheets is a sure winner! It has been a great interactive (program) so far" (GS). A majority of the participants considered Zoom a delightful platform (GS). Some suggested the addition of virtual reality technology to make the experience feel more realistic (GS). As indicated in the literature review, virtual conference tools enable synchronous communication globally and contribute to the effectiveness of a virtual conference (Koivulahti-Ojala and Käkölä, 2012; Mulyani, 2019). The new digital platforms provide opportunities for attendees to interact and to exchange information in real time (Porpiglia et al., 2020). Therefore, technology enablers are considered the foundation for a successful virtual conference.

\section{Positive Interactions and Communication Between Organizers and Participants (Social Enablers)}

Organizational characteristics are critical to positive interactions and communication in a virtual conference. "Distinctive illustrations and processes" were identified as success factors (IP04). The selection and role of the moderators are also important. A respondent indicated that they attended sessions that were chaired by individuals whose work they admired (IP07). Thus, the active engagement of researchers from the lean community during the conference was important, as mentioned by another respondent (IP10).

The social enablers for good interactions and communication were also confirmed in the analysis of the Google Sheets data. Participants indicated that a moderator's judgement, skill, and knowledge were enablers because they influenced their facilitation of the session. A participant stated in Google Sheets: "Great job moderating and facilitating ... nice job in sharing time with each presenter and making adjustments on the basis of yesterday's feedback" (GS). Good preparation was also highlighted. One participant indicated, "I also did some tests using Google forms to complete these data. Sometimes it worked; sometimes it didn't" (GS). Compliance with the conference requirements contributed to the effectiveness of the live discussions. This was a recurring perspective (GS, IP02). Previous studies have also confirmed the contributions of participant social interactions, team training, organizational effects, and moderator skills to the success of virtual conferences (Lindeblad et al., 2016; Vandenberg and Reese, 2011; White, 2014).

\section{Logical Process Design and Control}

The respondents observed that logical process design and control contributed to the success of a virtual conference. Their views on design and control, such as the use of single rather than parallel sessions varied. For example, one interviewee said, "I liked that the online version didn't have parallel sessions. This made it easier for me to follow my topics of interest" (IP02). Some participants appreciated the selection of high-quality papers for the plenary session discussions (IP05). Others claimed that some of the sessions discussed too many papers. Some indicated that holding sessions across five consecutive workdays was exhausting and incompatible with their work and other commitments (IP01; IP06).

The smooth workflow of the conference were appreciated by some of the respondents. For example, one respondent stated, "Access to the papers for each session was seamless. There were several advantages of such a system" (IP05). One of the major changes was the requirement for attendees to watch a video presentation of each conference paper prior to the discussions. This process change elicited varying opinions. Some respondents thought that they did not have enough time to watch the videos before the sessions (IP03). Others said that the change allowed more time for discussion (IP10). Similar opinions were expressed in Google Sheets. The debate over this process led to design 
improvements. In subsequent sessions, each author gave a brief introduction to their paper, thereby improving the process. Welldesigned processes contribute to the success of a virtual conference (Vandenberg and Reese, 2011).

Time management is important because a virtual meeting without breaks will not be successful (White, 2014). This was revealed in the analysis of the Google Sheets and semi-structured interview data. The participants suggested that session duration should be informed by the number of papers and, thus, the time needed for presentation and discussion (IP01; GS).

\section{Knowledge Management}

A majority of the respondents considered the knowledge presentation and sharing at this virtual conference a success. One participant stated that the conference provided updates and insights into the status of lean construction ([LC] IP09). Another said: "More implicit knowledge was transferred [here] than at non-remote conferences" (IP08). This is also reflected in the analysis of the Google Sheets data. The topic discussions enabled knowledge transformation, and the gaming sessions enabled the participants to develop a greater understanding of LC-related concepts. Open access facilitated knowledge dissemination (GS; CN).

Knowledge management is defined as the process of acquiring, storing or sharing, diffusing, and applying tacit and explicit knowledge within and outside an organization to effectively achieve organizational goals (Magnier-Watanabe and Senoo, 2008). It is crucial for competitive success (McQueen, 1998). Magnier-Watanabe (2011) asserted that knowledge management enablers contribute to the Kaizen process. Kaizen, a Japanese word, means continual incremental improvement (Masaaki, 1986). This virtual conference followed the Kaizen process, and knowledge management contributed to its success.

\section{Barriers or Challenges to the Success of Virtual Conferences}

The primary factors that inhibited the conference workflow were another theme that emerged from the semi-structured interviews. The subthemes are presented below.

\section{Connectivity and Collaboration Within Time Limits}

Achieving connectivity and collaboration within a time limit was a subtheme that emerged from the interviews. The participants claimed that there were limited opportunities for informal networking (IP05; IP07). A participant stated, "The main challenge was how to connect with fellow researchers in a virtual environment with time limits. Discussing research on similar subjects, networking, and finding ways to collaborate were difficult" (IP01). This barrier was also found in the Google Sheets analysis. The time constraints and the characteristics of virtual conferences pose difficulties for engaging participants in discussions (GS). This perspective is consistent with those of previous studies. Achieving the effects of face-to-face social interactions at virtual events is a challenge (Bidmon et al., 2020).

\section{Capture of Real-Time Audience Reactions}

The semi-structured interviews revealed that the difficulty in capturing audience reactions in real time was a barrier. A participant stated that real-time reactions to the authors' work were captured more easily in face-to-face presentations (IP07). An author stated, "I think that the greatest challenge is establishing communication channels between the audience and the paper authors and making the presentations interesting in a remote format" (IP10). Specific areas in Google Sheets were set up to collect participant feedback. This was helpful because capturing real-time responses in a virtual conference is difficult.

\section{Participant Engagement}

The engagement of the participants is crucial to the success of the virtual conferences. Low participant engagement occurred for several reasons. The online conference offers the advantages of easier and more flexible participation because of the lack of a fixed location; however, this also increases the randomness of the participation. Online meetings were described as "a new phenomenon for people to accept" (IP10). Other issues include differences in time zones and variations in internet connectivity across countries. In addition, a great deal of reading and video watching was required before the discussions. This was not feasible for most people. A respondent in the semi-structured interviews said, "A huge upfront effort was needed to participate in the discussions and follow them" (IP08).

The need to engage more people in the discussions was reiterated in the feedback on Google Sheets. A virtual academic conference is believed to have the potential to engage and to connect professional peers and facilitators across geographical boundaries (Murphy and Reushle, 2012). However, it is still considered a difficult medium for achieving social effects (Bidmon et al., 2020).

\section{Benefits of Virtual Conferences}

The benefits of virtual conferences are the major outcomes of continual improvement activities. The first virtual IGLC conference yielded many benefits. The three main benefits that emerged from the semi-structured interviews are presented below.

\section{Expanded Influence of the International Group of Lean Construction Community}

The first benefit was the expansion of the LC community's influence. A respondent said, "I think this conference expanded the horizons of the IGLC community and provided more space for environmental engineering, technological and digital advances, industrialized building, and other subjects that can benefit significantly from the incorporation of lean construction" (IP01). The online conference is a feasible approach for maintaining a sense of community in difficult situations (IP10). 


\section{Contribution to Lean Construction Knowledge and Identification of Future Directions}

This virtual conference facilitated the participants' understanding of the status of the field, the implementation of LC knowledge, and the identification of future directions. A respondent stated: "This is an opportunity to find out other people's ideas and approaches to the topics" (IP03). Another said: "This conference provides me with an update and insights into the current status of lean construction from experts and experienced professionals in the LC field" (IP09). Yet another participant stated, "The researchers and professors who participated spread the acquaintance knowledge to their colleagues and students" (IP07).

\section{Contribution to Environmental Sustainability}

The virtual conference is cost-effective and environmentally friendly because the participants do not have to travel. Participation in a virtual conference is easier than in an inperson conference. A participant stated, "I would not attend this conference if it were not virtual" (IP03). An attendee from India indicated that a virtual conference was more sustainable than a physical conference (IP05). Virtual meetings have been found to contribute to the reduction of carbon dioxide emissions (Arnfalk et al., 2016). The positive effects were indicated in Google Sheets through comments such as "facilitates wider dissemination," "focus opportunities for networking and collaboration," and "the gaming sessions deepened the understanding of relevant concepts" (GS). The virtual conference could be used to reduce travel costs, to decrease negative environmental effects, and to improve collaboration and flexibility (Lindeblad et al., 2016). The benefits include memories of a positive experience that could inform the organization of future virtual meetings.

\section{External Environmental Factors}

In the semi-structured interviews, the respondents mentioned the conference organizers' efficient response to the pandemic (IP09). Another said that virtual conferences were a feasible option for the survival of conferences under difficult circumstances (IP10). The COVID-19 pandemic has contributed to the development of virtual conferences, which are becoming the norm (Rubinger et al., 2020; Viglione, 2020). Some good practices of virtual conferences can be used as options in the post-COVID-19 era (GS). A public health crisis, such as COVID-19, was one of the emergent external environmental factors in the semi-structured interviews and document analysis.

\section{Results of Document Analysis and Participant Observation at the Virtual International Group for Lean Construction Conference}

The authors were participants and observers of the sessions. The observation was unstructured to obtain broader relevant evidence as it emerged (Daniel et al., 2019). Relevant documents, such as Google Sheets, were also analyzed. The themes and subthemes that emerged from Google Sheets and the semi-structured interviews were confirmatory. Some of the themes and subthemes are discussed below.

\section{Drivers}

Drivers are the primary reasons and sources of motivation for continual improvement process activities, such as improving workflow and meeting participants' needs to ensure satisfaction.

\section{Participant Needs and Satisfaction}

The organizers conceived of the conference as a continual improvement process. They adhered to lean thinking, attended to user and participant needs, regularly acknowledged problems, and continually made improvements during the conference.

A plus-delta tool was set up in the daily Google document to obtain the attendees' feedback on their needs, ideas, and suggestions. Some semi-structured questions were provided in Google Sheets to elicit their reactions. The questions included the following: "What went well today?" "What should we continue to do?" "What did not go well today?" "What specifically should we do tomorrow or next year?" (GS). Participant reactions, needs, and satisfaction were the most important drivers of this virtual conference. Consequently, the organizers were motivated to perform continual improvement activities.

\section{Workflow Improvements}

The conference organization was driven by lean thinking, with a focus on workflow improvement and user satisfaction. An email to the attendees stated, "You can see it took us some effort to figure out the workflow, streamline it, and set it up so that $150+$ people can all participate in the conversation! It'll be interesting!" (OF; PO). Followup actions were tracked in Google Sheets to ascertain the participants' improvement requests, and ideas. Furthermore, the organizers answered the participants' questions promptly (GS).

\section{Inputs}

Some emergent subthemes, such as conference spending, human resources, new ideas and concepts, and external knowledge sources, were generalized as input factors (Ozorhon, 2013). Regarding conference spending, the organizers and reviewers provided their services at no cost. An online conference costs much less than an in-person conference. This reduces the financial difficulties to some extent and contributes to the success of a virtual conference. The human resources investment in the online conference was significant. Files had to be uploaded before the conference, and the sessions needed to be video recorded. The final format of the conference proceedings needed to be determined after the conference was over. All of these activities required a great deal of time and effort before, during, and after the conference.

New ideas and concepts, as well as external knowledge sources, were also important inputs for the success of this virtual conference (IP05). This view emerged in the analysis of the Google Sheets and participant observation data (PO; GS). The Google Sheets submissions included many new ideas and types of information, which were important inputs for the improvement activities. 


\section{Continual Improvement Activities}

The continual improvement activities were the improved processes or products of this virtual conference. The following three sub-themes emerged: integrated design, lean thinking, and lessons learned.

\section{Integrated Design}

Integrated design guarantees the delivery of targeted outcomes and informs an efficient project management plan (Azari and Kim, 2016; Lee et al., 2005). The integration design activities enabled the integration of key members in the early stages of the design process, intense collaboration to define the project goals, and participation in some important aspects of sustainable construction and design (Azari and Kim, 2016).

The organizers' close communication and cooperation in the early stages of the conference facilitated the logical planning and design of the entire process (PO). It laid a good foundation for the successful realization of the goals. As was previously mentioned, the seamless integration, which was manifested as a system, was appreciated by many attendees (GS). Integrated design was also identified as a solution for a smooth conference workflow.

\section{Lean Construction}

The principles of LC, a new approach to construction project management (Koskela, 1992), have also been applied to project delivery systems (Ballard 2000; Ballard 2006). A large VIAC enables the use of new methods to organize the resources to complete an isolated task within a given cost and time constraint to achieve established goals. This conforms to the definition of a project; thus, a large virtual conference could be likened to a project. Traditional project delivery systems focus solely on task transformation. However, lean project delivery systems address not only product delivery but also flow and value transformation (Koskela et al., 2002).

The theme was LC, which guided the organization of this virtual conference. The focus was task transformation, workflow, and the realization of user value. It was a continual improvement process. The organizers observed the progression of the conference and made continual progress on the basis of the participants" feedback (PO). A participant said, "It is overwhelming to know that there are so many Kaizens as we go along day after day. It needs a very organized and synchronized team to put this together and a leader who gives enough empowerment for them to make decisions on the spot!” (GS)

\section{Lessons Learned}

Lessons learned are one of the improvement activities of this virtual conference. The IGLC hopes to become a learning organization through continual reflection and improvement. (Senge 1990, p. 3), who proposed the concept, described learning organizations as "organizations where people continually expand their capacity to create the results they truly desire, where new and expansive patterns of thinking are nurtured, where collective aspiration is set free, and where people are continually learning how to learn together." The organizers used the lessons learned to revise the process as the conference progressed. These lessons can be applied to future conferences (GS; PO).

\section{Development of a Model for a Successful Virtual International Academic Conference Rationale for the Proposed Model}

Previous studies have focused on the influential factors in and effects of VIACs. There is no clear classification of these factors, and a systematic model of the organization of a successful VIAC has not hitherto been developed. In the COVID-19 era, there is a need for a dynamic model to guide future conferences.

The aims of the proposed model are as follows:

- Identify and classify the influential factors.

- Provide a nonprescriptive approach for organizing a successful VIAC.

- Enable the use of the success pattern as a dynamic continual improvement process.

\section{Theoretical Foundation of the Model}

The organizers approached the conference as a continual improvement process. It should be noted that continual improvement is an innovation activity (Ozorhon, 2013). Thus, the innovation process model (Ozorhon, 2013; Ozorhon et al., 2014) informed the development of the proposed model for hosting a successful VIAC.

\section{A Model for a Successful Virtual International Academic Conference}

This case analysis of the first virtual IGLC conference was the basis for the development of a dynamic VIAC model (Figure 3). Evidence was gathered from documents, semi-structured interviews, participant observation, and a literature review.

The model classifies the key success factors as drivers, inputs, enablers, effects, and barriers. The underlying principle of this model is continual improvement. The conference was also influenced by external environmental factors, such as the COVID-19 pandemic. The components and indicators are summarized in Table 4.

This nonprescriptive model provides conference organizers with a structured approach to organizing a successful VIAC. It is not rigid; thus, it is adaptable. The model is explained below.

\section{Drivers and Continual Improvement Activities}

The driving factors, the sources and causes of motivation, directly influence the continual improvement activities. In this virtual conference, participant requirements, satisfaction, and workflow motivated the conference organizers. This was a dynamic process because user satisfaction and requirements continued to unfold, and the improvement activities were ongoing. For example, the IGLC conference organizers' collection of participant expectations through Google Sheets during the conference enabled the improvement activities to be performed in a timely manner. 


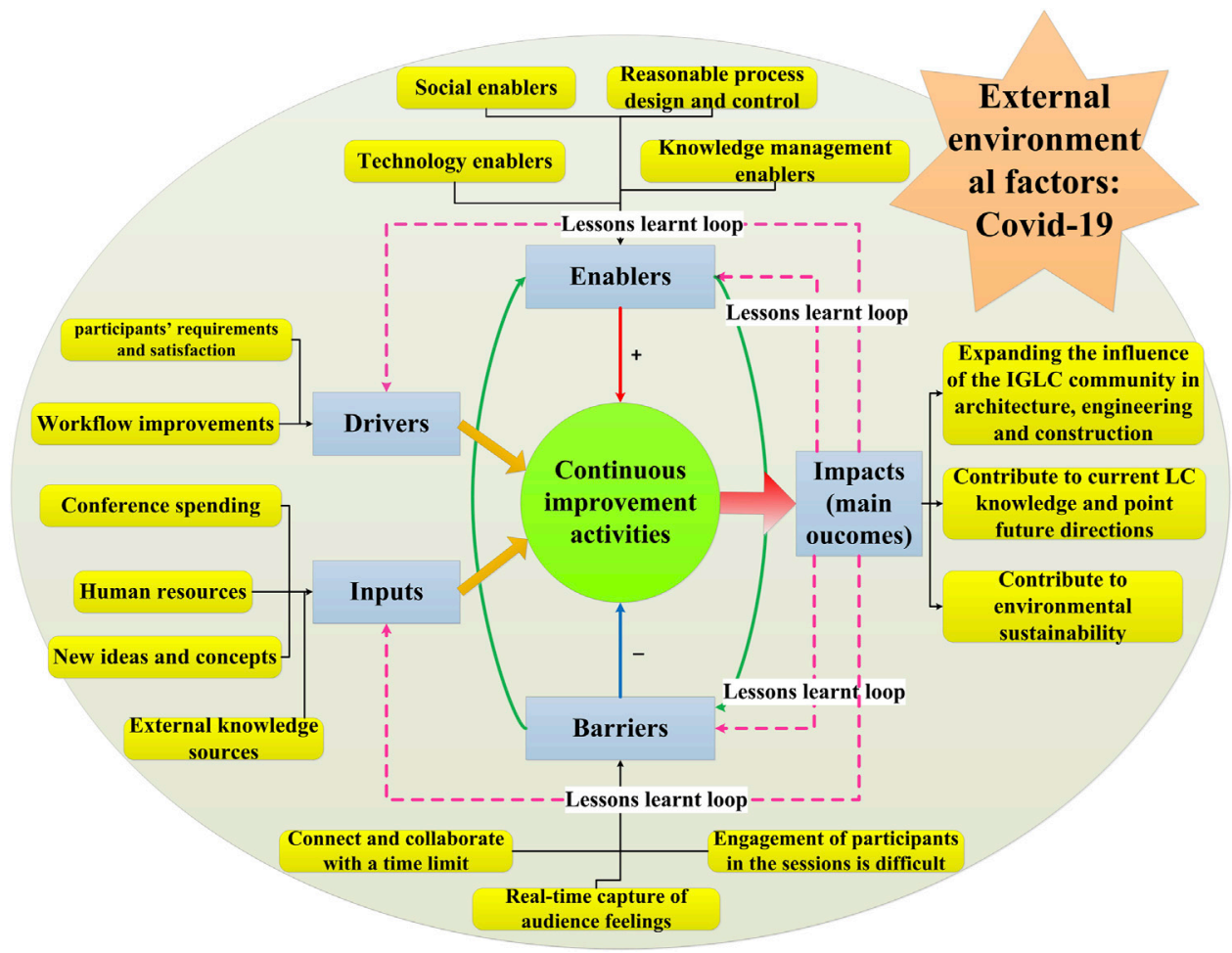

FIGURE 3 | A model for a virtual international academic conference.

TABLE 4 | Components of a successful virtual international academic conference model.

Components

External environmental factors

Drivers

Inputs

Enablers

Effects

Barriers

Continual improvement activities

\section{Description}

Politics, economy, competition, social conditions, public health crises, such as COVID-19

Primary reasons and sources of motivation for continual improvement, e.g., workflow improvements and participants' needs and satisfaction

Conference spending, human resources, new ideas and concepts, and external knowledge sources

Key success factors and mitigation of the negative effects of the barriers or challenges through technological, social, and knowledge enablers, as well as logical process design and control

Major outcomes of continual improvement activities: positive (a good experience) or negative (lessons learnt for application in future virtual conferences)

Primary inhibiting factors in the conference workflow

Continual improvement activities: improved conference processes or products, such as integrated design, lean construction, and lessons learned

\section{Inputs and Continual Improvement Activities}

Inputs are the resources that form the basis for and have a direct effect on continual improvement activities. They include conference spending, human resources, new ideas and concepts, and external knowledge sources. As resources continue to accumulate, the basic conditions for continual improvement activities will also continue to improve. However, having more resources may not be beneficial because it can sometimes increase costs. Therefore, it is necessary to determine the optimal balance point.

\section{Effects and Continual Improvement Activities}

Effects are the major outcomes of continual improvement activities. As illustrated in the model, this virtual conference had three main outcomes with interrelated effects. First, the conference expanded the knowledge within the IGLC and AEC communities. The successful execution of IGLC 28 online and the feedback from the participants indicate the viability of virtual academic conferences. These encouraging results provide a compelling argument for hosting virtual conferences in the future. Many participants indicated that future conferences should adopt a hybrid model, which would provide an opportunity for both online participation and face-toface participation. This is a positive outcome for not only the IGLC community but also the organizers of academic conference organizers in AEC and other sectors. Had IGLC 28 been cancelled, as was the case with other construction engineering conferences, because of the COVID-19 pandemic, the 
opportunity for knowledge creation would have been delayed or lost. In addition, VIACs support environmental sustainability because of reduced travel needs.

\section{Enablers, Barriers, and Continual Improvement Activities}

Enablers are the factors that contribute to continual improvement activities. Barriers are the impediments. The positive effects of enablers can mitigate the negative effects of barriers to achieve a balance. For example, the lack of in-person engagement is considered a barrier to the success of an online conference. However, it can be mitigated by technology enablers. For example, virtual reality technology could enhance the real-time experience of attendees. However, this may increase costs.

\section{External Environmental Factors}

In this case study of IGLC 28, a virtual conference, the COVID-19 pandemic was found to be the most influential external environmental factor. It had an effect on all the other factors in this virtual conference. The pandemic led to cost savings for most participants; however, the organizers required additional resources, and external knowledge. Specifically, the organizers adjusted the input resources to the new operation mode. The pandemic also increased the need for the development of virtual technologies and platforms and social enabling factors, as well as a logical conference design and control process. It also created many barriers. The conference had a meaningful impact on environmental sustainability, such as a reduction in carbon emissions, because of the elimination of the need for long-distance travel. In addition, individuals who were unlikely to attend an in-person conference gained the opportunity to participate in a virtual one. Other external environmental factors, such as political and economic conditions, competition, and social conditions, should also be considered in future VIACs.

\section{CONCLUSION}

This study aimed to explore the key success factors in VIACs. It also proposed a model to guide the organization of future VIACs. The analysis revealed the following enabling factors: technology, social enablers, logical process design and control, and knowledge management. They are not new; however, technology and process design and control were found to be the most significant factors. The findings also revealed the limitations of VIACs. They include the inability to capture the participants' real-time responses, limited networking opportunities for participants, and

\section{REFERENCES}

Arnfalk, P., Pilerot, U., Schillander, P., and Grönvall, P. (2016). Green IT in Practice: Virtual Meetings in Swedish Public Agencies. J. Clean. Prod. 123, 101-112. doi:10.1016/j.jclepro.2015.08.063

Azari, R., and Kim, Y.-W. (2016). Integration Evaluation Framework for Integrated Design Teams of green Buildings: Development and Validation. J. Manag. Eng. 32 (3), 04015053. doi:10.1061/(asce)me.1943-5479.0000416

Ballard, G. (2000). Lean Project Delivery System. White Paper \#8, Berkeley: Lean Construction Institute, 8, 1-6. difficulties in managing participants in different time zones. In the future, organizers will need to address these limitations. An option could be to use virtual reality technology to increase networking opportunities for participants. The study found that knowledge creation in VIACs is similar to that in physical conferences. In addition, VIACs contribute to environmental sustainability.

This study contributes to knowledge creation in construction and engineering management. It expands the understanding of the key success factors in VIACs through a case study of IGLC 28. It provides new insights into the execution of a successful VIAC in AEC. It classified the key success factors of virtual conferences as driving factors, enabling factors, and barriers, which have not received much attention in previous studies.

The proposed model conceptualizes the virtual conference as a continual improvement process. This provides new insights and a theoretical basis for the organization of successful VIACs. This study also supports sustainable knowledge development in engineering management. It is one of the first to propose a model for organizing a VIAC. The proposed model can inform practice because it elucidates the factors to be considered in the execution of a VIAC. It is not rigid; thus, it can be adapted to other virtual AEC conferences with similar structures.

A single-case study was conducted; however, the evidence was gathered from multiple sources, for corroboration. It enhances the understanding of the factors that influence the success of VIACs. The proposed model could be adapted for future virtual academic conferences on AEC. In future research, significance analysis could be used to determine the influence of these factors on the success of VIACs.

\section{DATA AVAILABILITY STATEMENT}

The raw data supporting the conclusions of this article will be made available by the authors, without undue reservation.

\section{AUTHOR CONTRIBUTIONS}

YF: Conceptualization, Methodology, Formal analysis, Project administration, Writing - original draft, Writing - review and editing. ED: Conceptualization, Methodology, Project administration, Writing - original draft, Writing - review and editing.

Ballard, G. (2006). Rethinking Project Definition in Terms of Target Costing [Conference Presentation]," in Proceedings of the 14th Annual Congress, International Group for Lean Construction. Santiago, Chile, July 2006, 77-90. doi:10.1016/j.procs.2021.01.314

Beranek, P. M., and Martz, B. (2005). Making Virtual Teams More Effective: Improving Relational Links. Team Perform. Manag. 11 (5-6), 200-213. doi:10.1108/13527590510617774

Bidmon, C., Meath, C., and Bohnsack, R. (2020). Organizing a Virtual Conference Changed the Way We Think about Academic Exchange. Nature. doi:10.1038/ d41586-020-01896-3

Bryman, A. (2012). Social Research Methods. United Kingdom: Oxford University Press. 
Chen, M., Liou, Y., Wang, C.-W., Fan, Y.-W., and Chi, Y.-P. J. (2007). TeamSpirit: Design, Implementation, and Evaluation of a Web-Based Group Decision Support System. Decis. Support Syst. 43 (4), 1186-1202. doi:10.1016/j.dss.2005.07.008

Daniel, E. I., Pasquire, C., and Dickens, G. (2019). Development of Approach to Support Construction Stakeholders in Implementation of the Last Planner System. J. Manag. Eng. 35 (5), 04019018. doi:10.1061/(asce)me.19435479.0000699

Erickson, T., Sadat Shami, N., Kellogg, W. A., and Levine, D. W. (2011). Synchronous Interaction Among Hundreds: An Evaluation of a Conference in an Avatar-Based Virtual EnvironmentConference on Human Factors in Computing Systems. New York, USA, 296-303.

Hara, N., Bonk, C. J., and Angeli, C. (2000). Content Analysis of Online Discussion in an Applied Educational Psychology Course. Instr. Sci. 28 (2), 115-152. doi:10.1023/a:1003764722829

IGLC (2020). The International Group for Lean Construction. Available at: (Accessed July 16, 2020).

Koch, M., Fischer, M. R., Tipold, A., and Ehlers, J. P. (2012). Can Online Conference Systems Improve Veterinary Education? A Study about the Capability of Online Conferencing and its Acceptance. J. Vet. Med. Edu. 39 (3), 283-296. doi:10.3138/jvme.0911-097r

Koivulahti-Ojala, M., and Käkölä, T. (2012). "Design, Implementation, and Evaluation of a Virtual Meeting Tool-Based Innovation for UML Technology Training in Global Organizations," in Proceedings of the Annual Hawaii International Conference on System Sciences. Maui, HI, USA, 3980-3989. doi:10.1109/HICSS.2012.198

Koskela, L., Howell, G., Ballard, G., and Tommelein, I. (2002). The Foundations of Lean Construction, Design and Construction: Building in Value. Chapter 14. Oxford, UK: Butterworth-Heinemann, Elsevier.

Koskela, L. (1992). Application of the New Production Philosophy to Construction. CIFE Technical Report \#72. September, California: Stanford University. doi:10.22260/isarc1992/0016

Lee, E.-B., Harvey, J. T., and Thomas, D. (2005). Integrated Design/construction/ operations Analysis for Fast-Track Urban Freeway Reconstruction. J. Constr. Eng. Manage. 131 (12), 1283-1291. doi:10.1061/(asce)0733-9364(2005)131:12(1283)

Li, S., Fang, Y., and Wu, X. (2020). A Systematic Review of Lean Construction in mainland China. J. Clean. Prod. 257, 120581. doi:10.1016/j.jclepro.2020.120581

Lindeblad, P. A., Voytenko, Y., Mont, O., and Arnfalk, P. (2016). Organisational Effects of Virtual Meetings. J. Clean. Prod. 123, 113-123. doi:10.1016/ j.jclepro.2015.08.058

Macfarlane, B. (2007). Defining and Rewarding Academic Citizenship: the Implications for university Promotions Policy. J. Higher Edu. Pol. Manag. 29 (3), 261-273. doi:10.1080/13600800701457863

Magnier-Watanabe, R., and Senoo, D. (2008). Organizational Characteristics as Prescriptive Factors of Knowledge Management Initiatives. J. Knowl. Manag. 12 (1), 21-36. doi:10.1108/13673270810852368

Magnier-Watanabe, R. (2011). Getting Ready for Kaizen: Organizational and Knowledge Management Enablers. Vine 41 (4), 428-448. doi:10.1108/ 03055721111188520

Masaaki, I. (1986). Kaizen: The Key to Japan's Competitive Success. New York: McGraw-Hill/Irwin.

McCarthy, J. F., McDonald, D. W., Soroczak, S., Nguyen, D. H., and Rashid, A. M. (2004). Augmenting the Social Space of an Academic Conference," in Proceedings of the ACM Conference on Computer Supported Cooperative Work. Chicago, Illinois, USA. doi:10.1145/1031607.1031615

McQueen, R. (1998). "Four Views of Knowledge and Knowledge Management," in Proceedings of the Fourth Americas Conference on Information Systems, Baltimore, Maryland. August 14-16 1998, 609-611.

Mulyani, R. A. (2019). New Meeting Form in the Digital Working Environment Era. Int. J. Innovative Tech. Exploring Eng. 9 (1), 2700-2705. doi:10.35940/ ijitee.A4849.119119

Murphy, A., and Reushle, S. (2012). "Following the Sun: Sustainable Conferencing in a Climate of Change," in Annual Conference of the Australian Society for Computers in Tertiary Education. Retrieved from: http://www.academia.edu/2224027/ Following_the_Sun_Sustainable_conferencing_in_a_climate_of_change (Accessed June 5, 2021).

Navarro, C. (2001). Partage de l'information en situation de coopération à distance et nouvelles technologies de la communication : bilan de recherches récentes. Travail Humain 64 (4), 297-319. doi:10.3917/th.644.0297
Nawaz, A., Waqar, A., Shah, S., Sajid, M., and Khalid, M. (2019). An Innovative Framework for Risk Management in Construction Projects in Developing Countries: Evidence from Pakistan. Risks 7 (1), 24. doi:10.3390/risks7010024

Nawaz, A., Su, X., Barkat, M. Q., Asghar, S., Asad, A., Basit, F., et al. (2020a). Epidemic Spread and its Management through Governance and Leadership Response Influencing the Arising Challenges Around COVID-19 in Pakistan-A Lesson Learnt for Low Income Countries with Limited Resource. Front. Public Health 8, 1-15. doi:10.3389/fpubh.2020.573431

Nawaz, A., Su, X., Din, Q. M. U., Khalid, M. I., Bilal, M., and Shah, S. A. R. (2020b). Identification of the H\&S (Health and Safety Factors) Involved in Infrastructure Projects in Developing Countries-A Sequential Mixed Method Approach of OLMT-Project. Ijerph 17 (2), 635. doi:10.3390/ijerph17020635

Neustaedter, C., Venolia, G., Procyk, J., and Hawkins, D. (2016). “To Beam or Not to Beam," in Proceedings of the ACM Conference on Computer Supported Cooperative Work. CA, USA. doi:10.1145/2818048.2819922

Ozorhon, B., Abbott, C., and Aouad, G. (2014). Integration and Leadership as Enablers of Innovation in Construction: Case Study. J. Manage. Eng. 30 (2), 256-263. doi:10.1061/(asce)me.1943-5479.0000204

Ozorhon, B. (2013). Analysis of Construction Innovation Process at Project Level. J. Manage. Eng. 29 (4), 455-463. doi:10.1061/(asce)me.1943-5479.0000157

Pookulangara, S., and Koesler, K. (2011). Cultural Influence on Consumers' Usage of Social Networks and its' Impact on Online purchase Intentions. J. Retail. Consum. Serv. 18 (4), 348-354. doi:10.1016/j.jretconser.2011.03.003

Porpiglia, F., Checcucci, E., Autorino, R., Amparore, D., Cooperberg, M. R., Ficarra, V., et al. (2020). Traditional and Virtual congress Meetings during the COVID-19 Pandemic and the post-COVID-19 Era: Is it Time to Change the Paradigm? Eur. Urol. 78 (3), 301-303. doi:10.1016/j.eururo.2020.04.018

Richards, J., Edwards, K., Lackey, M., Wallace, L., Calleson, J., Barber, C., et al. (2012). Collaborative Learning and Technology Skills Development: Evaluation of an Online Annual Grantee Meeting. Matern. Child. Health J. 16 (7), 1549-1552. doi:10.1007/s10995-011-0901-y

Rienks, R., Zhang, D., Gatica-Perez, D., and Post, W. (2006). "Detection and Application of Influence Rankings in Small Group Meetings," in ICMI06: 8th International Conference on Multimodal Interfaces, (New York, USA: Association for Computing Machinery), 257-264. doi:10.1145/ 1180995.1181047

Rubinger, L., Gazendam, A., Ekhtiari, S., Nucci, N., Payne, A., Johal, H., et al. (2020). Maximizing Virtual Meetings and Conferences: a Review of Best Practices. Int. Orthopaedics (Sicot) 44 (8), 1461-1466. doi:10.1007/s00264020-04615-9

Senge, P. (1990). The Fifth Discipline: The Art and Practice of the Learning Organization. New York: Doubleday.

Siggelkow, N. (2007). Persuasion with Case Studies. Amj 50 (1), 20-24. doi:10.5465/amj.2007.24160882

Simpson, J., and Nielsen, J. (2005). The 2005 Npt Review Conference. Nonproliferation Rev. 12 (2), 271-301. doi:10.1080/10736700500378901

Spilker, M., Prinsen, F., and Kalz, M. (2020). Valuing Technology-Enhanced Academic Conferences for Continuing Professional Development. A Systematic Literature Review. Prof. Dev. Edu. 46 (3), 482-499. doi:10.1080/ 19415257.2019.1629614

Stambough, J. B., Curtin, B. M., Gililland, J. M., Guild, G. N., Kain, M. S., Karas, V., et al. (2020). The Past, Present, and Future of Orthopedic Education: Lessons Learned from the COVID-19 Pandemic. The J. Arthroplasty 35 (7), S60-S64. doi:10.1016/j.arth.2020.04.032

Starr-Glass, D. (2014). "Moderating the Effective Co-creation of Knowledge in Asynchronous Online Conferences," in Building Online Communities in Higher Education Institutions: Creating Collaborative Experience. Editors C. N. Stevenson and J. C. Bauer (Hershey, PA: IGI-Global), 258-278. doi:10.4018/978-1-4666-5178-4.ch014

Sugiyama, Y., Matsuo, T., Shibata, A., Iwamoto, H., and Hochin, T. (2019). Analysis of Participants to the International Conferences Held in Japan and its Related Factors. 8th Int. Congress Adv. Appl. Inform. (Iiai-aai), 811-814. doi:10.1109/IIAI-AAI.2019.00165

Vandenberg, L., and Reese, L. (2011). Virtual Training for Virtual success: Michigan State University Extension's Virtual Conference. J. Ext. 49 (6), Retrieved from: https://www.learntechlib.org/p/110528/ (Accessed August 3, 2021).

Viglione, G. (2020). How Scientific Conferences Will Survive the Coronavirus Shock. Nature 582 (7811), 166-167. doi:10.1038/d41586-020-01521-3 
Wang, W., Bai, X., Xia, F., Bekele, T. M., Su, X., and Tolba, A. (2017). From Triadic Closure to Conference Closure: The Role of Academic Conferences in Promoting Scientific Collaborations. Scientometrics 113 (1), 177-193. doi:10.1007/s11192-017-2468-x

White, M. (2014). The Management of Virtual Teams and Virtual Meetings. Business Inf. Rev. 31 (2), 111-117. doi:10.1177/0266382114540979

World Health Organization (2020). Coronavirus (COVID-19) Data. Available at: (Accessed October 17, 2020).

Yin, R. K. (2014). Case Study Research: Design and Methods. 5th ed. Thousand Oaks, CA: SAGE Publications.

Conflict of Interest: The authors declare that the research was conducted in the absence of any commercial or financial relationships that could be construed as a potential conflict of interest.
Publisher's Note: All claims expressed in this article are solely those of the authors and do not necessarily represent those of their affiliated organizations, or those of the publisher, the editors and the reviewers. Any product that may be evaluated in this article, or claim that may be made by its manufacturer, is not guaranteed or endorsed by the publisher.

Copyright (C) 2021 Fang and Daniel. This is an open-access article distributed under the terms of the Creative Commons Attribution License (CC BY). The use, distribution or reproduction in other forums is permitted, provided the original author(s) and the copyright owner(s) are credited and that the original publication in this journal is cited, in accordance with accepted academic practice. No use, distribution or reproduction is permitted which does not comply with these terms. 